\title{
Commentary: The devil is in the details
}

\author{
Thoralf M. Sundt, MD
}

From the Division of Cardiac Surgery, Massachusetts General Hospital, Boston, Mass; Corrigan Minehan Heart Center, Massachusetts General Hospital, Boston, Mass; and Department of Surgery, Harvard Medical School, Boston, Mass.

Disclosures: Author has nothing to disclose with regard to commercial support.

Received for publication Nov 26, 2018; accepted for publication Nov 26, 2018; available ahead of print Jan 16, 2019.

Address for reprints: Thoralf M. Sundt, MD, Division of Cardiac Surgery, Massachusetts General Hospital, Edward D. Churchill Professor of Surgery, Harvard Medical School, Corrigan Minehan Heart Center, 55 Fruit St, Boston, MA 02114 (E-mail: tsundt@mgh.harvard.edu).

J Thorac Cardiovasc Surg 2019;157:2214-5

$0022-5223 / \$ 36.00$

Copyright (c) 2018 by The American Association for Thoracic Surgery

https://doi.org/10.1016/j.jtcvs.2018.11.091

Recognizing the rapidly changing landscape of interventional options for the treatment of valvular heart disease as well as significant gaps in care for patients with these conditions, representatives of the American College of Cardiology, under the auspices of their Task Force on Health Policy and Systems of Care, convened several years ago a multidisciplinary roundtable of cardiologists, imagers, advanced practitioners, surgeons, industry representatives government officials, and patient advocacy groups to discuss the challenges in the diagnosis and treatment of valvular heart disease in the United States. The aim was to lay a foundation for formulating a scalable approach to optimizing care for patients. Issues ranging from underdiagnosis and misdiagnosis to access to care were aired, as were appropriate quality metrics and shared decision making regarding surgical and transcatheter treatments. For better (the argument being consistency) or worse (the problem being confusion), this was done in parallel with a separate effort to write an updated expert consensus systems of care document establishing operator and institutional requirements for transcatheter aortic valve replacement.

The aim of the effort, ably led by 2 noninterventional expert clinical cardiologists, was to elevate the level of care for all patients while preserving or improving access. Inspired by the success seen in improving trauma care through the establishment of trauma centers decades ago and by the more recent development of comprehensive stroke networks, the group formulated a proposal to establish criteria for designation as primary (level II) and comprehensive (level I) centers. Importantly, the document by Nishimura and colleagues ${ }^{1}$ appearing in this issue of the Journal makes no effort to restrict care to such centers, nor does it argue for limiting the number of such designated centers. This is where the valve centers document differs significantly - and importantly-from the transcatheter aortic valve replacement document authored by Bavaria and colleagues. ${ }^{2}$ In fact, the best possible outcome of this

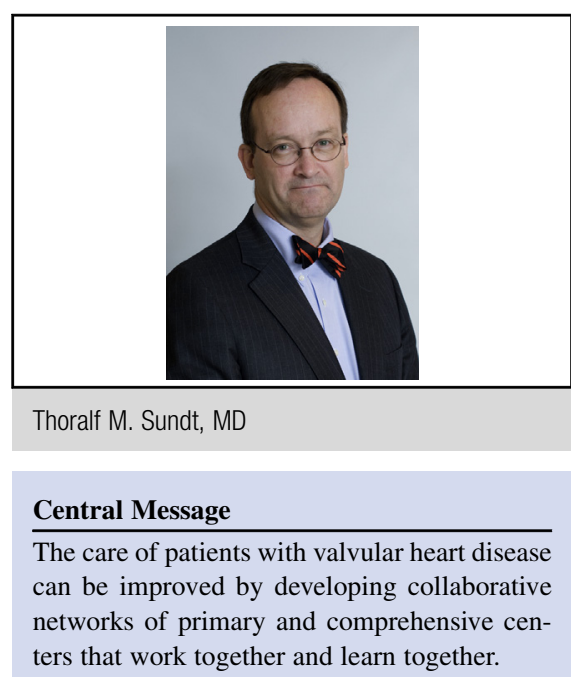

See Article page e327.

document would be the spread of expertise among an ever-expanding web of an increasing number of highquality centers as a result of participation in a regional network. Valve disease today is underdiagnosed as well as undertreated. Networks such as those proposed here would likely draw more patients into appropriate care.

The devil, of course, is in the details. Nishimura and colleagues ${ }^{1}$ did their best to create a document that is inclusive and supportive, not restrictive. Recommendations are meant to be just that, recommendations and not mandates. It is, however, hoped that the criteria enunciated in the document defining what should be available in a primary or comprehensive center will facilitate physicians in advocating for resources and infrastructure support from hospital and clinic administrators who are interested in such designations, just as has happened in the past for cancer centers, trauma centers, and stroke centers. Efforts were also made to focus on true quality metrics, rather than simply volume criteria such as a target set for mitral repair rate.

This will likely be a controversial document. The hope is that this is the first step toward openly discussing how we can achieve the quality improvement for valvular heart disease that has been seen in trauma and stroke care. They seem to have kept the devil in his place!

\section{References}

1. Nishimura RA, O'Gara PT, Bavaria JE, Brindis RG, Carroll JD, Kavinski CJ, et al. 2018 AATS/ACC/ASE/SCAI/STS expert consensus systems of care document: a proposal to optimize care for patients with valvular heart disease. J Thorac Cardiovasc Surg. 2019;157:e327-54. 
2. Bavaria JE, Tommaso CL, Brindis RG, Carroll JD, Deeb GM, Feldman TE, et al. 2018 AATS/ACC/SCAI/STS Expert Consensus Systems of Care Document: Operator and Institutional Recommendations and Requirements for Transcatheter Aortic Valve Replacement: A Joint Report of the American
Association for Thoracic Surgery, the American College of Cardiology, the Society for Cardiovascular Angiography and Interventions, and the Society of Thoracic Surgeons. J Am Coll Cardiol. 2018 Jul 18. pii: S0735-1097(18) $35377-4$. 